Gerbecks, J., Baliatsas, C., Yzermans, C.J., Smit, L.A.M., Huss, A., Heederik, D.J.J., Dückers, M.L.A. Prevalence of non-specific health symptoms in livestock dense areas: Looking beyond respiratory conditions. International Journal of Hygiene and Environmental Health: 2020, 230, 113603

$\begin{array}{lll}\text { Postprint version } & : & 1.0 \\ \text { Journal website } & : & \text { https://www.sciencedirect.com/science/article/abs/pii/S1438463920305 } \\ & & 496 ? v i a \% 3 D i h u b \\ \text { Pubmed link } & : & \text { https://pubmed.ncbi.nlm.nih.gov/32882646/ } \\ \text { DOI } & : & 10.1016 / j . i j h e h .2020 .113603\end{array}$

This is a Nivel certified Post Print, more info at nivel.nl

\title{
Prevalence of non-specific health symptoms in livestock dense areas: Looking beyond respiratory conditions
}

\author{
J. Gerbecks ${ }^{a, *,}$ C. Baliatsas ${ }^{a}$, C.J. Yzermans ${ }^{a}$, L.A.M. Smit ${ }^{b}$, A. Huss ${ }^{\text {b }}$, D.J.J. \\ Heederik ${ }^{b}$, M.L.A. Dückers ${ }^{a}$ \\ a Netherlands Institute for Health Services Research, Utrecht, the Netherlands \\ b Institute for Risk Assessment Sciences (IRAS), Utrecht University, the Netherlands
}

\begin{abstract}
The aim of this study was to gain more insight in the association between prevalence of diverse acute non-specific symptoms (NSS) and livestock density as a possible risk factor among residents of livestock-dense and non-dense regions, taking into account sociodemographic factors and psychological morbidity. Prevalence of NSS and psychological morbidity were assessed for the year 2017, based on electronic health records from 39 general practices in the Netherlands. The study group consisted of people who lived in rural areas with high numbers of livestock ( $n=74093$ ), while the control group included people in rural areas with low numbers of livestock $(n=50139)$. For a large portion of the study group, exposure estimates (to livestock) were calculated. Multiple logistic multilevel regression analyses were performed. Two methods were used: 1) area comparisons between study and control areas in relation to health problems, and 2) estimates of livestock exposure (to goats, poultry, pigs, and cattle) within the study area. It was found that prevalence of diarrhea, headache, sleep disturbance, respiratory symptoms, and skin problems were higher in the study group. The data suggest that there may be a protective effect of livestock exposure: in general, there was a lower risk of NSS closer to livestock (within the exposure analyses). The study suggests that the previously identified higher risk of respiratory health problems in livestock dense areas might also apply to the prevalence of various other NSS. Longitudinal research taking into account different or more individual and contextual characteristics could possibly elucidate why prevalence of NSS in closer proximity to livestock is lower compared to people who live further away, whilst a more overarching analysis indicated that living in livestock dense areas was associated with more NSS.
\end{abstract}


Gerbecks, J., Baliatsas, C., Yzermans, C.J., Smit, L.A.M., Huss, A., Heederik, D.J.J., Dückers, M.L.A. Prevalence of non-specific health symptoms in livestock dense areas: Looking beyond respiratory conditions. International Journal of Hygiene and Environmental Health: 2020, 230, 113603

\section{Introduction}

The high population density (Statline, 2019) combined with high concentration of farms (Statline, 2018) in the Netherlands has raised questions about how livestock farms affect human health. Livestock farms are a source of various emissions, such as particulate matter, endotoxins, and ammonia. Acute infections and chronic illnesses have recently been linked to residents of livestock dense areas (Borlée et al., 2017; Kalkowska et al., 2018; Maassen et al., 2016; Post et al., 2019; Van der Star et al., 2018). Furthermore, a variety of zoonotic pathogens are associated with both livestock farms and human health conditions (Morakinyo et al., 2016; Smit et al., 2012; Uiterwijk et al., 2017; Zomer et al., 2017). The vast majority of studies on livestock exposure and human health mainly focused on respiratory health problems (Baliatsas et al., 2017; Post et al., 2019; Van Dijk et al., 2016, 2017), while conditions and symptoms in other organ systems have been understudied.

Non-specific symptoms (NSS) are acute (though often recurrent) health problems that are very common in the general population and not necessarily associated with a specific disease (Van den Berg, 2007); More than 50\%of the self-reported health problems seem to be non-specific in nature (Van den Berg, 2007). Non-specific symptoms range from physical symptoms such as abdominal pain, to neurological outcomes such as sleep problems and concentration difficulties. Such symptoms can be caused by multiple factors and are often attributed to different environmental exposures (Spurgeon et al., 1996), such as electromagnetic fields (Baliatsas, 2015; Bogers et al., 2018), noise (Zijlema et al., 2015), and odors from agricultural facilities (Boers et al., 2016; Zock et al., 2018). Specifically regarding the latter, different sources of noise, such as tractors, machinery, or animals, have been detected on farms (Williams et al., 2015), while Radon et al. (2007) concluded that prevalence of self-reported asthma symptoms, nasal allergies, and wheezing was higher among people who experienced odor annoyance from livestock farms. In addition, Hooiveld et al. (2015) showed that people with higher levels of perceived odor annoyance are at higher risk of reporting diverse health symptoms, including sleep problems, dizziness, lower back pain, stress related symptoms, and stomach ache. Psychological factors could also contribute to the experience of NSS, within the environmental health context: For instance, Villeneuve et al. (2009) found that individuals who lived closer to farming operations had a higher depression rate and were more likely to worry about the health effects of environmental pollutants.

Nevertheless, it cannot be ruled out that zoonotic diseases may also play a role in the occurrence of NSS. Livestock are the primary source of zoonotic outbreaks, such as Q fever and avian influenza (Henningsen et al., 2003; Smit et al., 2012). The symptoms of Q fever (and sequalae) can overlap with many NSS, e.g. fatigue, headache, muscle aches, and non-productive coughing (Van den Brom et al., 2015); It is therefore likely that a number of patients are not diagnosed with $Q$ fever, but rather with the manifested symptoms.

This study aims to examine whether living in the proximity of a livestock farm is related to a higher prevalence of NSS, compared to areas situated further away from livestock farms. Using a large primary care database, the following research questions are addressed: 1) What is the difference in prevalence of NSS between people who live in livestock dense areas and people who live in non-dense areas, taking into account the possible influence of socio-demographic factors, and psychological morbidity? 2) Is there an association between prevalence of NSS and livestock exposure?

\section{Materials and methods}

\subsection{Study design and population}

Data for this cross-sectional study were obtained for the year 2017 from the Primary Care Database (PCD) of the Netherlands Institute for Health Services Research (NIVEL). Each inhabitant of the Netherlands is required to register at a general practice in the broader vicinity of residence, so 
Gerbecks, J., Baliatsas, C., Yzermans, C.J., Smit, L.A.M., Huss, A., Heederik, D.J.J., Dückers, M.L.A. Prevalence of non-specific health symptoms in livestock dense areas: Looking beyond respiratory conditions. International Journal of Hygiene and Environmental Health: 2020, 230, 113603

the population listed in family practice can be used as the denominator in epidemiological studies (van der Lei et al., 1993). Therefore these data are a representative coverage of the general population's health. Morbidity was registered according to the International Classification of Primary Care (ICPC) (Lamberts et al., 1987).

\subsection{Ethics}

The NIVEL PCD meets Dutch regulations on data protection and laws on use of health data for epidemiological research purposes (Dutch Civil Law, Article 7:458). A trusted third party (Stichting Informatievoorziening Zorg: IVZ, Houten, NL) ensured separation of medical information and personal information at all times.

\subsection{Study areas and control areas - Ecological comparisons}

This study used data from the "Livestock Farming and Neighbouring Residents Health (VGO)-III" study [VGO3-study] (Yzermans et al., 2018). For this study, electronic health records (EHRs) from 39 general practices were used. All practices were located in rural municipalities in the Netherlands (not urbanized or hardly urbanized), which include municipalities with fewer than 30,000 residents, or an urbanization degree of 4 and 5, according to the categorization of the Statistics Netherlands (Statline, 2015). The 'study area' (21 GPs) refers to livestock-dense rural regions in the provinces Overijssel, Gelderland, and Utrecht, while the 'control area' (18 GPs) refers to five other provinces with substantially lower livestock farm density.

\subsubsection{Estimates of livestock exposure}

For the study area only, the data file 'Bestand Agrarische Bedrijfssituatie' (BAB) 2016 (agricultural business situation) was used to obtain information on livestock density. The BAB is a nationwide data file constructed by the Netherlands Enterprise Agency (RVO). Within the file, all known locations of active agricultural sites, companies and stables are listed (Netherlands Enterprise Agency, 2019). For every respondent in the study population, the distances from the home address to the closest goat, poultry, pig and cow farm were estimated by using the coordinates of homes and farms. The following exposure variables were analyzed: 1) presence of goats within 500, 1000, or $2000 \mathrm{~m}$ from the home address, 2) presence of poultry within these buffers, 3) presence of pigs within these buffers, and 4) presence of cattle within these buffers. Cut-off values for the four types of animals were used to remove very small 'hobby' farms from the dataset. These cut-off values were $<50$ goats, $<25$ pigs, $<250$ poultry, and $<5$ cattle. Every farm with numbers of animals below these cut-off values were set to zero (Borlée et al., 2017, online supplement Table E1). Data on livestock estimates were available for 66,948 individuals in the study area.

\subsection{Symptom assessment}

Prevalence of NSS was measured by whether or not an individual was registered with a particular symptom in the year 2017. Prevalence estimates were based on episodes of illness. Each episode contains all patient encounters for a particular health problem within a specific period of time (Nielen et al., 2019). A 'symptom-free' period is taken into account, which is the period in which it is likely that a patient will visit the GP again if a medical complaint persists and determines whether ICPC records belong to the same episode. In some cases, in the present analyses, multiple ICPC-codes were clustered to form one health problem. The ICPC codes that were included (also within clusters) can be found in Appendix A, Table 1. The ICPC distinguishes between depression and anxiety disorder, and depressed and anxious feelings. For construction of the variable 'psychological morbidity', only the disorder codes (P76 and P72) were used, after which the constructed variable was dichotomized. 
Gerbecks, J., Baliatsas, C., Yzermans, C.J., Smit, L.A.M., Huss, A., Heederik, D.J.J., Dückers, M.L.A. Prevalence of non-specific health symptoms in livestock dense areas: Looking beyond respiratory conditions. International Journal of Hygiene and Environmental Health: 2020, 230, 113603

\subsection{Covariates}

Information on demographic characteristics was obtained from patients' health records. The following variables were used for analyses: age (polynomial), registry duration (continuous), gender (male/female), study group (dichotomous), and socio-economic status (SES) (interval). For sensitivity analyses, psychological morbidity (dichotomous) was included. SES was retrieved via the Netherlands Institute for Social Research (SCP) (2019). In this case, SES is the social status of the neighborhood, based on average income, percentage low income, percentage low educated, and percentage of unemployed people in the neighborhood. The SCP provides relative status scores on a four-digit postal code level: the mean score is 0 . A positive score thus means that a neighborhood has a higher status than average, a negative score is lower than average.

\section{[Table 1]}

\subsubsection{Statistical analyses}

Multilevel logistic regression analyses were performed to account for the hierarchical structure of the data (patients nested within general practices). Prevalence of each individual symptom was the dependent variable. The independent were the group type (study group versus control group) for the ecological comparison, and livestock exposure estimates (for the individual level analyses). In addition, the number of investigated symptoms were analyzed as count variable, following the approach of Yzermans et al. (2016). For this outcome variable, negative binomial (multilevel) regression was performed. All analyses were adjusted for gender, age (polynomial), registry duration, SES and anxiety or depression disorder. For each regression model, odds ratios (OR) or incidence rate ratios (IRR) were calculated at a significance level of $p \leq .05$ (95\% confidence intervals ( $\mathrm{Cl}$ ).

Several sensitivity analyses were also performed in order to test whether the findings of the primary analyses would remain robust, such as the addition as covariates of three ICPC codes that indicate social problems (Z03: housing/neighborhood problems, Z05: work problems, Z10: health care system problems), and carrying out cross-classified models for the ecological comparisons, adding municipality as an extra level. (Under 'work problems', a number of different personal issues/situations can be registered, that could affect health, such as excessive workload, problematic relationship with colleagues, impending employment termination, and occupational exposure to noise and/or toxic substances.) Furthermore, we used the number of animals as (continuous) independent variable and also split the animal number at the median among the exposed into a high and low exposure group and re-analyzed the examined health outcomes. Analyses were performed with STATA version 15.0 (StataCorp LP, College Station, TX, USA).

\section{Results}

\subsection{Ecological comparisons}

\subsubsection{Sample characteristics}

Table 1 displays the sample characteristics for the control and study area. In total, the study group consisted of 74,093 patients, and the control group included 50,139 patients. Gender did not differ statistically significant between the control group and the study group $(p=.183)$. The average age in the study group was 41.3 years, in the control group $42(p=.000)$. There was a significant $(p=.000)$ difference between the control and study areas' average SES, with a lower score in the control group.

In Graph 1, the prevalence for the control and study areas is displayed. The most prevalent symptoms in general were respiratory symptoms, abdominal pain, general weakness/tiredness, pain/pressure chest, and low back symptom. 
Gerbecks, J., Baliatsas, C., Yzermans, C.J., Smit, L.A.M., Huss, A., Heederik, D.J.J., Dückers, M.L.A. Prevalence of non-specific health symptoms in livestock dense areas: Looking beyond respiratory conditions. International Journal of Hygiene and Environmental Health: 2020, 230, 113603

\subsubsection{Differences in symptom prevalence between areas with high and low livestock density}

In the ecological comparison (Table 2), significant differences between the study and control group in the prevalence of diarrhea, headache, sleep disturbance, respiratory symptoms, and skin complaints were identified. People in the study group were at a higher risk of experiencing (one of these) five health problems. Results were almost identical when adjusted for psychological morbidity, indicating that prevalence of NSS is not explained by psychological morbidity. For readability, only the results of the complete model (including psychological morbidity) are presented.

With regard to the socio-demographic variables, there was an almost consistently higher chance for women, and also a higher chance for elderly people to experience any of the NSS. This was also the case for people with psychological morbidity. Additional correction for registered social problems (related to housing/neighborhood, work and health care), and adding municipality as an extra level in cross-classified models did not alter the results (data not shown).

\subsection{Livestock exposure comparisons}

Regarding livestock density in the study areas, $1.3 \%$ of the sample lived within $500 \mathrm{~m}$ from goat farms, $6 \%$ within $1000 \mathrm{~m}$, and $29.9 \%$ of the study population lived within $2000 \mathrm{~m}$ from goat farms. For poultry farms, these were $10.1 \%, 32.7 \%$ and $68.3 \%$ respectively, for pig farms, $16.6 \%, 51 \%$, and $90.7 \%$, and for cattle $43.8 \%, 85 \%$, and $99.5 \%$, meaning that almost every patient in the exposed group lived within $2000 \mathrm{~m}$ from cattle.

\section{[Graph 1] [Table 2]}

\subsubsection{Association between health symptoms and exposure to livestock}

\subsubsection{Goats.}

Results on the associations NSS and exposure to livestock estimates are shown in Table $3-6$. Regarding presence of goats (Table 3) only the OR for eye problems for the buffer 0-2000 $\mathrm{m}$ was statistically significant, with a higher risk for people exposed to goats (compared to the nonexposed). Prevalence of general weakness/tiredness, low back symptoms, and headache increased with closer distance, whereas the opposite trend was observed for the prevalence of eye problems, muscle pain, vertigo/dizziness, and disturbance of memory/concentration/orientation.

\subsubsection{Poultry}

In Table 4, regarding poultry, there were several statistically significant odds ratios; general weakness/tiredness $(2000 \mathrm{~m})$, palpitations/awareness of heart $(2000 \mathrm{~m})$, vertigo/dizziness $(2000 \mathrm{~m})$, disturbance of memory/concentration/orientation (both $500 \& 1000 \mathrm{~m}$ ), respiratory symptoms (500 $\mathrm{m})$ and also sum of NSS $(500 \mathrm{~m})$. Risks for muscle pain and headache increased with closer proximity, whereas risks for abdominal pain, diarrhea, eye problems, pain/pressure chest, low back symptom, and feeling/behaving irritable/angry decreased with closer proximity.

\subsubsection{Pigs.}

In Table 5, regarding pigs, palpitations/awareness of heart (1000 m), sleep disturbance (500 m), disturbance of memory/concentration/orientation $(500 \mathrm{~m})$, respiratory symptoms $(500 \mathrm{~m})$ and sum of NSS (500 m) were significant. Within these groups, the risk of experiencing NSS is significantly lower than for the people who live further away than respectively 500 or $1000 \mathrm{~m}$.

\subsubsection{Cattle.}

In Table 6, regarding cattle, the following OR were significant in the 0-500 $\mathrm{m}$ buffer; abdominal pain, diarrhea, pain/pressure chest, palpitations, muscle pain, sleep disturbance, respiratory 
Gerbecks, J., Baliatsas, C., Yzermans, C.J., Smit, L.A.M., Huss, A., Heederik, D.J.J., Dückers, M.L.A. Prevalence of non-specific health symptoms in livestock dense areas: Looking beyond respiratory conditions. International Journal of Hygiene and Environmental Health: 2020, 230, 113603

symptoms and sum of NSS. For sum of NSS, the OR for the buffer 0-2000m was significant as well. There is a trend of lower risk of NSS with closer distance for muscle pain, vertigo/dizziness, acute stress reaction, feeling/behaving irritable/angry, and sleep disturbance. For the other NSS, there is no such trend in any direction.

For the majority of the significant ORs, risk of experiencing the NSS was lower for those exposed to livestock, compared to those not exposed. (This goes for all ORs, except for eye problems $(2000 \mathrm{~m})$ in Table 3, and muscle pain $(500 \mathrm{~m})$ and sum NSS (2000m) in Table 6.) For 10 out of 19 NSS, the risk at NSS decreases with closer proximity. For the other 9 NSS, there is no such trend in any direction.

\section{[Table 3] [Table 4].[Table 5] [Table 6]}

\section{Discussion}

This study examined differences in prevalence of NSS between residents of livestock dense areas and people who live in rural areas with much lower livestock density. This was first done by ecological comparison, taking into account the possible influence of socio-demographic factors and psychological morbidity. In addition, associations between prevalence of NSS and livestock exposure in the livestock dense regions were investigated. Results showed that prevalence of diarrhea, headache, sleep disturbance, respiratory symptoms and skin complaints were significantly higher among people who lived in livestock dense areas. However, prevalence of NSS was not significantly associated with exposure to livestock. The significant effects that have been found indicate a somewhat protective effect of livestock farms. In most occurrences, living in closer proximity to livestock was associated with a lower risk of experiencing NSS. In short, the area comparison indicated that exposed individuals are more often prone to NSS than non-exposed individuals, but within the exposed group, closer distance was associated with fewer NSS.

Since the prevalence and risk of several NSS appeared to be higher among residents of livestock dense areas (study group), it was reasonable to expect that closer proximity would indicate a higher prevalence. Interestingly, analyses with the exposure estimates did not verify these differences; the risk of experiencing NSS was more often smaller with closer proximity than it was higher with closer proximity. Similar health outcomes (Van Dijk et al., 2017). Considering that the vast majority of people in the exposed group lived within $2000 \mathrm{~m}$ from a farm/stable, it may be that the area comparison enabled a larger exposure contrast compared to the exposure estimates.

By using both an area comparison and exposure estimates, this study constructs a complete image of the relation between livestock and NSS in The Netherlands. The area comparison shows differences between exposed and non-exposed individuals, whereas the exposure estimates lead to a comparison within the exposed group (exposed individuals relative to one another, based on distance to livestock).

A strong body of evidence has shown that proximity to livestock farms can be associated with adverse health effects in humans, and with respiratory outcomes in particular (Baliatsas et al., 2017; Borlée et al., 2017; Kalkowska et al., 2018; Maassen et al., 2016; Post et al., 2019; Van den Berg, 2007; Van der Star et al., 2018; Van Dijk et al., 2016). The current study has some inconclusive results. Based on the area comparison, there are more health issues associated with livestock farms. This is in line with the limited evidence from previous studies; Hooiveld et al. (2015) found a higher prevalence of sleeping problems, dizziness, lower back pain, stress-related issues, and stomach ache in residents close to livestock farms in the Netherlands. However, they based their findings on selfreported data. In addition, a Canadian study found higher depression rates among people living close to a large livestock farm (Villeneuve et al., 2009), while another study in Canada suggested an association between livestock farming intensity and acute gastrointestinal symptoms (Febriani et al., 2009). 
Gerbecks, J., Baliatsas, C., Yzermans, C.J., Smit, L.A.M., Huss, A., Heederik, D.J.J., Dückers, M.L.A. Prevalence of non-specific health symptoms in livestock dense areas: Looking beyond respiratory conditions. International Journal of Hygiene and Environmental Health: 2020, 230, 113603

It currently remains unclear what a potential explanatory mechanism could be. Besides the possible contribution of livestock exposure, bio-psychosocial pathways might be of relevance. There is evidence that modeled odor exposure from livestock farming is associated with odor annoyance among neighbouring residents (Boers et al., 2016) and it has been suggested that odor annoyance from animal feeding operations could play a role in the occurrence of symptomatology among residents of livestock dense areas (Hooiveld et al., 2015). A recent survey also showed that living close to a larger number of farms or within $1 \mathrm{~km}$ of a goat farm was associated with a more negative attitude towards farming activities; negative attitudes were also associated with more self-reported symptoms (Borlée et al., 2019). Another explanation might be related to the protective effect of early life exposure to farming environments on the development of allergic diseases. Previous studies concluded that long-term and/or early life exposure to farming sites or products had a strong protective effect against development of asthma, hay fever, and atopic sensitisation (Riedler et al., 2001; Müller-Rompa et al., 2018). We should consider the chance that this protective effect of farms on allergic diseases is not limited to asthma, hay fever, and atopic sensitisation, but also is present with (some of the) NSS included in this study.

\subsection{Strengths and limitations}

In the present study two approaches were combined; an area comparison and use of exposure estimates. An important strength of this study is the use of recent data based on EHRs, which reduces the risk for selection bias, recall bias and outcome misclassification. Furthermore, multiple sensitivity analyses ensured that the operationalization of the variables did not affect the results. Because of the exploratory nature of this study, and the knowledge that NSS could co-occur with mental health problems (Leiknes et al., 2007; Villeneuve et al., 2009; Matalon et al., 2011; Spurgeon et al., 1996; Van Eck van der Sluijs et al., 2015), psychological morbidity was included as probable confounder of NSS to be as inclusive as possible.

The ICPC is a standardized classification system used by all general practitioners in the Netherlands. One limitation of using GP EHRs is that off hours visits to emergency departments of hospitals and clinics are not available in the data. However, facilities outside the general practice hours/emergency units only cover a very small part of the acute disorders in primary care. It is also highly unlikely for people to visit emergency departments of hospital off hours for symptoms examined in the present study such as concentration problems, vertigo, or sleep problems.

This was a first exploration of general practice-registered acute symptoms in relation to livestock presence, and only data from one time point was analyzed, which is a limitation of the current study. Another limitation of the cross-sectional design is the higher risk for reversed causality, to some extent. Using EHR also has its weak points when examining NSS: People who encounter non-specific health complaints do not necessarily present all their symptoms to the GP, therefore, data from EHR often give an underestimation of the true prevalence of health problems. It would be beneficial to examine exposure-estimates for larger buffers to see whether proximity matters between, for example, people located within $2000 \mathrm{~m}$ from a livestock farm, 2000-4000 m, and 4000-6000 m.

\section{Conclusions}

The study suggests that people living in livestock dense areas may experience more acute health symptoms. Longitudinal research taking into account different individual and contextual characteristics could possibly elucidate the mechanisms behind the occurrence of NSS in relation to livestock farms. 
Gerbecks, J., Baliatsas, C., Yzermans, C.J., Smit, L.A.M., Huss, A., Heederik, D.J.J., Dückers, M.L.A. Prevalence of non-specific health symptoms in livestock dense areas: Looking beyond respiratory conditions. International Journal of Hygiene and Environmental Health: 2020, 230, 113603

\section{Funding}

This study was conducted within the framework of the project "Livestock Farming and Neighbouring Residents Health (VGO)-III", funded by the Ministry of Health, Welfare and Sport and the Ministry of Agriculture, Nature and Food Quality of The Netherlands.

\section{Declaration of competing interest}

None declared.

\section{Acknowledgements}

We want to thank the participating GPs for their cooperation, Elsbeth de Leeuw-Stravers and Eeke Steenaart for communicating with the GPs and for their work on data extraction, and Mark Nielen and Rodrigo Davids for their work on the dataset. We would also like to thank our colleagues at NIVEL for their remarks on the manuscript.

\section{Appendix A. Supplementary data}

Supplementary data to this article can be found online at https://doi. org/10.1016/j.ijheh.2020.113603.

\section{References}

Baliatsas, C., Borlee, F., van Dijk, C.E., van der Star, B., Zock, J.P., Smit, L.A.M., et al.,2017. Comorbidity and coexisting symptoms and infections presented in general practice by COPD patients: does livestock density in the residential environment play a role? Int. J. Hyg Environ. Health 220 (4), 704-710. https://doi.org/10.1016/j. ijheh.2017.02.005.

Baliatsas, C., 2015. Non-specific physical symptoms in relation to actual and perceived exposure to electromagnetic fields (EMF): a multidisciplinary approach (Doctoral Dissertation). Retrieved from. https://www.nivel.nl/sites/default/files/2019-10/NI V\%201208.pdf.

Boers, D., Geelen, L., Erbrink, H., Smit, L.A., Heederik, D., Hooiveld, M., et al., 2016. The relation between modeled odor exposure from livestock farming and odor annoyance among neighboring residents. Int. Arch. Occup. Environ. Health 89 (3), 521-530. https://doi.org/10.1007/s00420-015-1092-4.

Bogers, R.P., van Gils, A., Clahsen, S.C.S., Vercruijsse, W., van Kamp, I., Baliatsas, C., et al., 2018. Individual variation in temporal relationships between exposure to radiofrequency electromagnetic fields and non-specific physical symptoms: a new approach in studying 'electrosensitivity'. Environ. Int. 121, 297-307. https://doi.org/10.1016/j.envint.2018.08.064.

Borlée, F., Yzermans, C.J., Aalders, B., et al., 2017. Air pollution from livestock farms is associated with airway obstruction in neighboring residents. Am. J. Respir. Crit. Care Med. 196 (9), 1152 1161. https://doi.org/10.1164/rccm.201701-00210C.

Borlée, F., Yzermans, C.J., Oostwegel, F.S.M., et al., 2019. Attitude toward livestock farming does not influence the earlier observed association between proximity to goat farms and self-reported pneumonia. Environmental Epidemiology 3 (2), e042. https://doi.org/10.1097/EE9.0000000000000041.

Febriani, Y., Levallois, P., Lebel, G., Gingras, S., 2009. Association between indicators of livestock farming intensity and hospitalization rate for acute gastroenteritis. Epidemiol. Infect. 137 (8), 1073-1085. https://doi.org/10.1017/S0950268808001647.

Henningsen, P., Zimmerman, T., Sattel, H., 2003. Medically unexplained symptoms, anxiety, and depression: a meta-analytic review. Psychosom. Med. 65 (4), 528-533. https://doi.org/10.1097/01.PSY.0000075977.90337.E7.

Hooiveld, M., van Dijk, C., van der Sman-de Beer, F., Smit, L.A., Vogelaar, M., Wouters, I. M., et al., 2015. Odour annoyance in the neighbourhood of livestock farming -perceived health and health 
Gerbecks, J., Baliatsas, C., Yzermans, C.J., Smit, L.A.M., Huss, A., Heederik, D.J.J., Dückers, M.L.A. Prevalence of non-specific health symptoms in livestock dense areas: Looking beyond respiratory conditions. International Journal of Hygiene and Environmental Health: 2020, 230, 113603

care seeking behaviour. Ann. Agric. Environ. Med. 22 (1), 55-61.

https://doi.org/10.5604/12321966.1141369.

Kalkowska, D.A., Boender, G.J., Smit, L.A.M., Baliatsas, C., Yzermans, J., Heederik, D.J. J., et al., 2018. Associations between pneumonia and residential distance to livestock farms over a five-year period in a large population-based study. PloS One 13 (7).

https://doi.org/10.1371/journal.pone.0200813.

Lamberts, H., Wood, M., 1987. International Classification of Primary Care. Oxford University Press, Oxford.

Leiknes, K.A., Finset, A., Moum, T., Sandanger, I., 2007. Course and predictors of medically unexplained pain symptoms in the general population. J. Psychosom. Res. 62 (2), 119-128. https://doi.org/10.1016/j.jpsychores.2006.08.009.

Maassen, K., Heederik, D., Yzermans, J., Hagenaars, T., Van der Hoek, W., 2016. Veehouderij en gezondheid omwonenden. RIVM.

Matalon, A., Kotliroff, A., Blumberg, G., Yaphe, J., Kitai, E., 2011. Non-specific symptoms as clues to changes in emotional well-being. BMC Fam. Pract. 12, 77. https://doi.org/10.1186/1471-229612-77.

Morakinyo, O.M., Mokgobu, M.I., Mukhola, M.S., Hunter, R.P., 2016. Health outcomes of exposure to biological and chemical components of inhalable and respirable particulate matter. Int. J. Environ. Res. Publ. Health 13 (6). https://doi.org/10.3390/ijerph13060592.

Müller-Rompa, S.E.K., Markevych, I., Hose, A.J., et al., 2018. An approach to the asthmaprotective farm effect by geocoding: good farms and better farms. Pediatr. Allergy Immunol. 29 (3), 275282. https://doi.org/10.1111/pai.12861.

Netherlands Enterprise Agency, 2019. Retrieved from. https://english.rvo.nl/ CP). SCP: The Hague. Last accessed July 24, 2019

http://www.scp.nl/Onderzoek/Lopend_onderzoek/A_Z_alle_lopende_onderzoeken/Statusscore $s$ (in Dutch).

Nielen, M.M.J., Spronk, I., Davids, R., et al., 2019. Estimating morbidity rates based on routine electronic health records in primary care: observational study. J. Med. Internet Res. 7 (3) https://doi.org/10.2196/11929.

Post, P.M., Hogerwerf, L., Huss, A., et al., 2019. Risk of pneumonia among residents living near goat and poultry farms during 2014-2016. PloS One 14 (10).

https://doi.org/10.1371/journal.pone.0223601.

Radon, K., Schulze, A., Ehrenstein, V., van Strien, R., Praml, G., Nowak, D., 2007. Environmental exposure to confined animal feeding operations and respiratory health of neighboring residents. Epidemiology 18 (3), 300-308. https://doi.org/10.1097/01.ede.0000259966.62137.84.

Riedler, J., Braun-Fahrländer, C., Eder, W., et al., 2001. Exposure to farming in early life and development of asthma and allergy: a cross-sectional survey. Lancet 358 (9288), 1129-1133.

Smit, L.A., Van der Sman-de Beer, R., Opstal-van Winden, A.W., et al., 2012. Q fever and pneumonia in an area with a high livestock density: a large population-based study. PloS One 7 (6). https://doi.org/10.1371/journal.pone.0038843.

Spurgeon, A., Gompertz, D., Harrington, J.M., 1996. Modifiers of non-specific symptoms in occupational and environmental syndromes. Occup. Environ. Med. 53 (6), 361-366. https://doi.org/10.1136/oem.53.6.361.

Statline, 2019. Bevolking; kerncijfers [data]. Accessed 2019-11-03. Available from. https://statline.cbs.nl/Statweb/publication/? $D M=S L N L \& P A=37296 n e d \& D 1=68 \& D 2=0,10,20,30,40,50,(I-1)-I \& V W=T$.

Statline, 2015. Kerncijfers wijken en buurten 2015. Retrieved from. https://opendata.cbs .nl/statline/\#/CBS/nl/dataset/83220NED/table?fromstatweb. 
Gerbecks, J., Baliatsas, C., Yzermans, C.J., Smit, L.A.M., Huss, A., Heederik, D.J.J., Dückers, M.L.A. Prevalence of non-specific health symptoms in livestock dense areas: Looking beyond respiratory conditions. International Journal of Hygiene and Environmental Health: 2020, 230, 113603

Statline, 2018. Landbouw; vanaf 1851. Accessed 2019-03-11. Available from. https://statline.cbs.nl/Statweb/publication/? DM=SLNL\&PA=71904ned\&D1=5-11,3345\&D2 $=162-166 \& H D R=G 1 \& S T B=T \& V W=T$.

Uiterwijk, M., Keur, I., Friesema, I., et al., 2017. Staat Van Zo“onosen 2017. RIVM. https://doi.org/10.21945/RIVM-2018-0112.

Van den Berg, B., 2007. Physical symptoms that are frequently unexplained among survivors of the Enschede fireworks disaster. General introduction (Doctoral Dissertation). Retrieved from. https://dspace.library.uu.nl/bitstream/handle/1874/20882/index.htm;jsessionid=60A1A12F40C C4D7F5831D1274883F5B4?se quence $=4$.

Van den Brom, R., Van Engelen, E., Roest, H.I.J., Van der Hoek, W., Vellema, P., 2015. Coxiella burnetii infections in sheep or goats: an opinionated review. Vet. Microbiol. 181 (1-2), 119. https://doi.org/10.1016/j.vetmic.2015.07.011.

Van der Star, B.J., van Dijk, C.E., Zock, J.P., Smit, L.A.M., Baliatsas, C., Heederik, D.J.J., et al., 2018. Healthcare utilisation prior to the diagnosis of inflammatory bowel diseases and the influence of livestock exposure: a longitudinal case-control study. PloS One 13 (4). https://doi.org/10.1371/journal.pone.0195305.

Van Dijk, C., Garcia-Aymerich, J., Carsin, A.E., Smit, L.A., Borlee, F., Heederik, D.J., et al., 2016. Risk of exacerbations in COPD and asthma patients living in the neighbourhood of livestock farms: observational study using longitudinal data. Int. J. Hyg Environ. Health 219 (3). https://doi.org/10.1186/s12890-019-0865-z.

Van Dijk, C.E., Zock, J.P., Baliatsas, C., Smit, L.A.M., Borlee, F., Spreeuwenberg, P., et al., 2017. Health conditions in rural areas with high livestock density: analysis of seven consecutive years. Environ. Pollut. 222, 374-382. https://doi.org/10.1016/j. envpol.2016.12.023.

Van Eck van der Sluijs, J., ten Have, M., Rijnders, C., et al., 2015. Meidcally unexplained and explained physical symptoms in the general population: association with prevalent and incident mental disorders. PloS One 10 (4). https://doi.org/10.1371/journal.pone.0123274.

Villeneuve, P.J., Ali, A., Challacombe, L., Hebert, S., 2009. Intensive hog farming operations and selfreported health among nearby rural residents in Ottawa, Canada. BMC Publ. Health 9, 330. https://doi.org/10.1186/1471-2458-9-330.

Williams, W., Brumby, S., Calvano, A., Hatherell, T., Mason, H., Mercer-Grant, C., et al., 2015. Farmers' work-day noise exposure. Aust. J. Rural Health 23 (2), 67-73. https://doi.org/10.1111/ajr.12153.

Yzermans, C.J., Smit, L.A.M., Heedering, D.J.J., Hagenaars, T.J., 2018. Veehouderij en gezondheid omwonenden III: longontsteking in de nabijheid van geiten- en pluimveehouderijen; actualisering van gegevens uit huisartspraktijken 2014 - 2016. Nivel, Utrecht (Report in Dutch).

Yzermans, J., Baliatsas, C., Van Dulmen, S., Van Kamp, I., 2016. Assessing non-specific symptoms in epidemiological studies: development and validation of the Symptoms and Perceptions Questionnaire. Int. J. Hyg Environ. Health 219 (1), 53-65. https://doi.org/10.1016/j.ijheh.2015.08.006.

Zijlema, W.L., Morley, D.W., Stolk, R.P., Rosmalen, J.G.M., 2015. Noise and somatic symptoms: a role for personal traits? Int. J. Hyg Environ. Health 218 (6), 543-549. https://doi.org/10.1016/j.ijheh.2015.05.001.

Zock, J.P., Verheij, R., Helbich, M., Volker, B., Spreeuwenberg, P., Strak, M., et al., 2018. The impact of social capital, land use, air pollution and noise on individual morbidity in Dutch neighbourhoods. Environ. Int. 121 (1), 453-460. https://doi.org/10.1016/j.envint.2018.08.064.

Zomer, T.P., Wielders, C.C., Veenman, C., Hengeveld, P., van der Hoek, W., de Greeff, S. C., et al., 2017. MRSA in persons not living or working on a farm in a livestock-dense area: prevalence and risk factors. J. Antimicrob. Chemother. 72 (3), 893-899. https://doi.org/10.1093/jac/dkw483. 
Gerbecks, J., Baliatsas, C., Yzermans, C.J., Smit, L.A.M., Huss, A., Heederik, D.J.J., Dückers, M.L.A. Prevalence of non-specific health symptoms in livestock dense areas: Looking beyond respiratory conditions. International Journal of Hygiene and Environmental Health: 2020, 230, 113603

\section{Tables and figures}

Table 1 Sample characteristics control and study group.

\begin{tabular}{lll}
\hline & Study group & Control group \\
\hline Female gender, N (\%) & $36,895(49.8)$ & $24,774(49.4)$ \\
Age, Mean (SD) & $41.36(24.2)$ & $42.05(23.5)$ \\
Socioeconomic status, Mean (SD) & $.16(.40)$ & $-.57(.89)$ \\
Psychological morbidity, N (\%) & $3240(4.4)$ & $2130(4.3)$ \\
Sum of NSS, Mean (SD) & $.51(.9)$ & $.42(.8)$ \\
\hline
\end{tabular}

Graph 1 Prevalence (\%) of assessed symptoms per study area in the year $2017(N=124,232)$

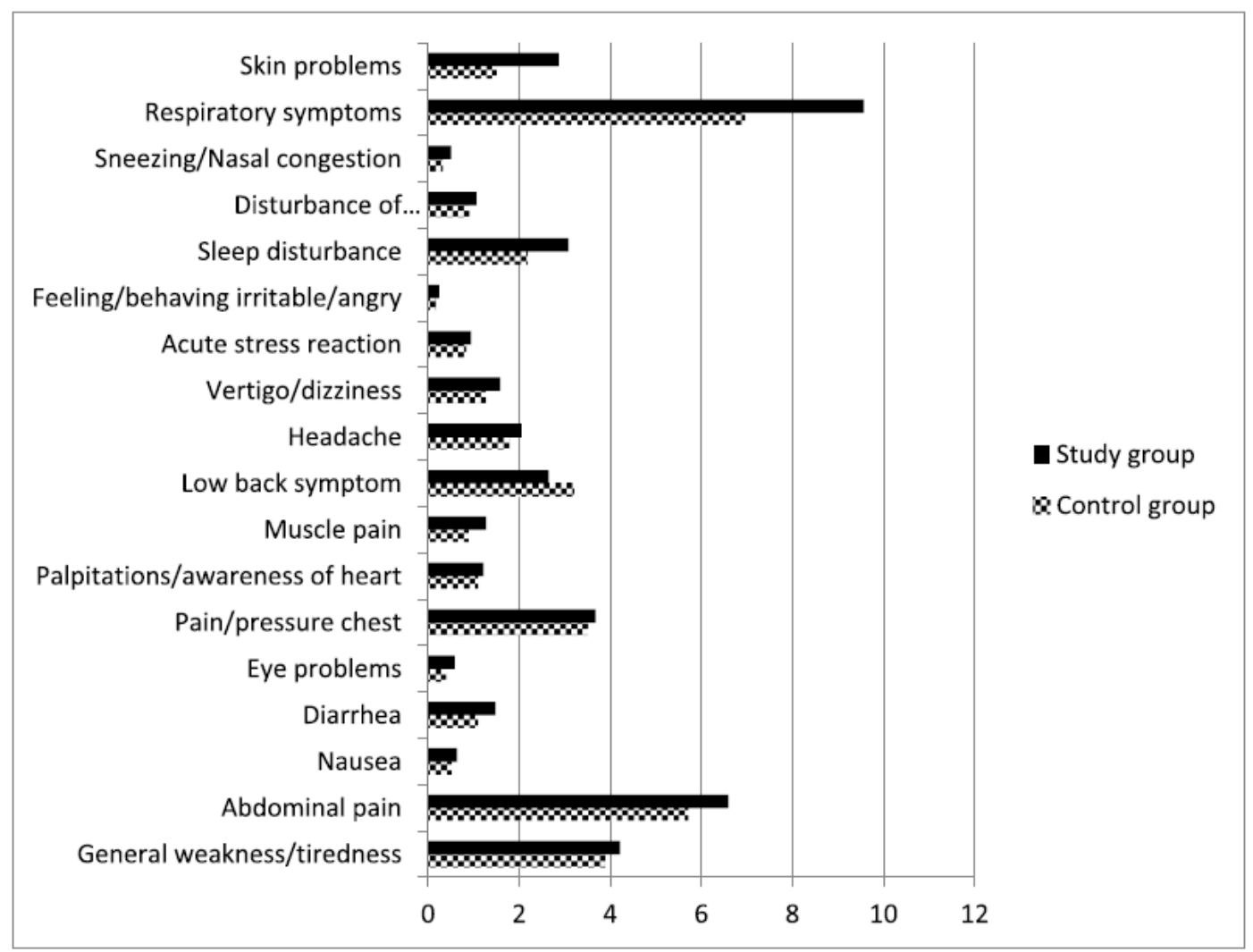


Gerbecks, J., Baliatsas, C., Yzermans, C.J., Smit, L.A.M., Huss, A., Heederik, D.J.J., Dückers, M.L.A. Prevalence of non-specific health symptoms in livestock dense areas: Looking beyond respiratory conditions. International Journal of Hygiene and Environmental Health: 2020, 230, 113603

Table 2 Differences (OR, 95\% Cl)a in various health symptoms between study and control areas, based on the total sample (statistically significant results in bold)*

\begin{tabular}{llll}
\hline & OR & CI & \\
\hline General weakness/tiredness & 1.07 & $(.89$ & $-1.28)$ \\
Abdominal pain & 1.21 & $(.97$ & $-1.50)$ \\
Nausea & 1.06 & $(.79$ & $-1.41)$ \\
Diarrhea & 1.26 & $(1.02$ & $-1.55)$ \\
Eye problems & 1.17 & $(.80$ & $-1.71)$ \\
Pain/pressure chest & 1.06 & $(.88$ & $-1.27)$ \\
Palpitations/awareness of heart & 1.10 & $(.86$ & $-1.41)$ \\
Muscle pain & 1.24 & $(.78$ & $-2.00)$ \\
Low back symptom & .88 & $(.64$ & $-1.21)$ \\
Headache & 1.17 & $(1.01$ & $-1.36)$ \\
Vertigo/dizziness & 1.19 & $(.89$ & $-1.60)$ \\
Acute stress reaction & .96 & $(.61$ & $-1.51)$ \\
Feeling/behaving irritable/angry & 1.21 & $(.75$ & $-1.96)$ \\
Sleep disturbance & 1.43 & $(1.12$ & $-1.84)$ \\
Disturbance of memory/concentration/orientation & .91 & $(.73$ & $-1.13)$ \\
Sneezing/nasal congestion & 1.27 & $(.75$ & $-2.15)$ \\
Respiratory symptoms & 1.35 & $(1.12$ & $-\mathbf{1 . 6 4 )}$ \\
Skin problems & $\mathbf{1 . 4 5}$ & $(1.00$ & $-2.09)^{\mathrm{x}}$ \\
Number of NSS ${ }^{-}$ & 1.18 & $(1.01$ & $-\mathbf{1 . 3 8 )}$ \\
\hline
\end{tabular}

${ }^{a}$ Model 1: Adjusted for age, gender, SES, and registry time of the patient in a general practice

Model 2: Model $1+$ mental health disorder

*p $<.05$

$\div$ Count variables, incidence rate ratios (IRR) are provided

${ }^{\mathrm{x}} \mathrm{p}=.05$

Table 3 Association (OR, 95\% Cl) between various health symptoms and presence of goats in 2017, in the study areas (statistically significant results in bold)*

\begin{tabular}{|c|c|c|c|c|c|c|c|c|c|}
\hline & \multicolumn{3}{|c|}{$500 \mathrm{~m}$} & \multicolumn{3}{|c|}{$1000 \mathrm{~m}$} & \multicolumn{3}{|c|}{$2000 \mathrm{~m}$} \\
\hline & OR & CI & & OR & CI & & OR & CI & \\
\hline General weakness/tiredness & 1.18 & $(.86$ & $-1.63)$ & 1.02 & $(.87$ & $-1.20)$ & .94 & $(.84$ & $-1.05)$ \\
\hline Abdominal pain & .86 & $(.63$ & $-1.19)$ & .97 & $(.84$ & $-1.12)$ & .97 & $(.88$ & $-1.07)$ \\
\hline Nausea & .93 & $(.20$ & $-1.97)$ & .84 & $(.53$ & $-1.34)$ & 1.07 & $(.82$ & $-1.40)$ \\
\hline Diarrhea & .63 & $(.30$ & $-1.34)$ & .82 & $(.60$ & $-1.12)$ & .84 & $(.69$ & $-1.02)$ \\
\hline Eye problems & .64 & $(.20$ & $-1.99)$ & 1.06 & $(.70$ & $-1.60)$ & 1.34 & $(1.00$ & $-1.79)$ \\
\hline Pain/pressure chest & .93 & $(.63$ & $-1.37)$ & .90 & $(.75$ & $-1.09)$ & 1.01 & $(.89$ & $-1.14)$ \\
\hline Palpitations/awareness of heart & .79 & $(.37$ & $-1.67)$ & 1.02 & $(.75$ & $-1.40)$ & .92 & $(.75$ & $-1.12)$ \\
\hline Muscle pain & .49 & $(.18$ & $-1.32)$ & .85 & $(.58$ & $-1.24)$ & .93 & $(.73$ & $-1.18)$ \\
\hline Low back symptom & 1.14 & $(.77$ & $-1.71)$ & .96 & $(.78$ & $-1.19)$ & .90 & $(.78$ & $-1.04)$ \\
\hline Headache & 1.13 & $(.72$ & $-1.81)$ & 1.10 & $(.88$ & $-1.37)$ & 1.00 & $(.86$ & $-1.16)$ \\
\hline Vertigo/dizziness & .60 & $(.28$ & $-1.28)$ & .90 & $(.68$ & $-1.20)$ & .99 & $(.82$ & $-1.19)$ \\
\hline Acute stress reaction & 1.10 & $(.54$ & $-2.24)$ & .97 & $(.68$ & $-1.38)$ & .98 & $(.78$ & $-1.24)$ \\
\hline Feeling/behaving irritable/angry & .56 & $(.08$ & $-4.06)$ & 1.51 & $(.82$ & $-2.80)$ & .97 & $(.62$ & $-1.52)$ \\
\hline Sleep disturbance & 1.10 & $(.73$ & $-1.66)$ & 1.14 & $(.93$ & $-1.39)$ & .95 & $(.83$ & $-1.10)$ \\
\hline Disturbance of memory/concentration/orientation & .97 & $(.46$ & $-2.07)$ & 1.09 & $(.78$ & $-1.53)$ & 1.12 & $(.94$ & $-1.34)$ \\
\hline Sneezing/nasal congestion & 1.30 & $(.53$ & $-3.19)$ & .90 & $(.58$ & $-1.41)$ & .91 & $(.66$ & $-1.23)$ \\
\hline Respiratory problems & .85 & $(.65$ & $-1.11)$ & .92 & $(.82$ & $-1.04)$ & 1.02 & $(.94$ & $-1.11)$ \\
\hline Skin problems & 1.08 & $(.72$ & $-1.61)$ & 1.10 & $(.93$ & $-1.32)$ & 1.06 & $(.92$ & $-1.21)$ \\
\hline Number of NSS $\div$ & .95 & $(.84$ & $-1.08)$ & .98 & $(.93$ & $-1.04)$ & .99 & $(.95$ & $-1.03)$ \\
\hline
\end{tabular}

a Adjusted for age, gender, SES, depression/anxiety disorder and registry time of the patient in a general practice

$\div$ Count variables, incidence rate ratios (IRR) are provided

" $\mathrm{p}<.05$ 
Gerbecks, J., Baliatsas, C., Yzermans, C.J., Smit, L.A.M., Huss, A., Heederik, D.J.J., Dückers, M.L.A. Prevalence of non-specific health symptoms in livestock dense areas: Looking beyond respiratory conditions. International Journal of Hygiene and Environmental Health: 2020, 230, 113603

Table 4 Association $(O R, 95 \% \mathrm{Cl})$ between various health symptoms and presence of poultry in 2017, in the study areas (statistically significant results in bold)*

\begin{tabular}{|c|c|c|c|c|c|c|c|c|c|}
\hline & \multicolumn{3}{|c|}{$500 \mathrm{~m}$} & \multicolumn{3}{|c|}{$1000 \mathrm{~m}$} & \multicolumn{3}{|c|}{$2000 \mathrm{~m}$} \\
\hline & OR & CI & & OR & CI & & OR & $\mathrm{CI}$ & \\
\hline General weakness/tiredness & .94 & $(.81$ & $-1.08)$ & .99 & $(.89$ & $-1.09)$ & .88 & $(.79$ & $-.98)$ \\
\hline Abdominal pain & .92 & $(.81$ & $-1.04)$ & .94 & $(.87$ & $-1.02)$ & 1.00 & $(.92$ & $-1.10)$ \\
\hline Nausea & .84 & $(.57$ & $-1.23)$ & .91 & $(.72$ & $-1.15)$ & .87 & $(.68$ & $-1.11)$ \\
\hline Diarrhea & .77 & $(.59$ & $-1.01)$ & .85 & $(.72$ & $-1.00)$ & .90 & $(.75$ & $-1.08)$ \\
\hline Eye problems & .76 & $(.51$ & $-1.14)$ & .84 & $(.66$ & $-1.07)$ & .99 & $(.74$ & $-1.32)$ \\
\hline Pain/pressure chest & .89 & $(.75$ & $-1.05)$ & .91 & $(.82$ & $-1.01)$ & 1.02 & $(.91$ & $-1.14)$ \\
\hline Palpitations/awareness of heart & .79 & $(.60$ & $-1.04)$ & .98 & $(.82$ & $-1.16)$ & .82 & (.69 & -.99) \\
\hline Muscle pain & 1.08 & $(.82$ & $-1.43)$ & .96 & $(.79$ & $-1.18)$ & .90 & $(.72$ & $-1.12)$ \\
\hline Low back symptom & .91 & $(.75$ & $-1.10)$ & .96 & $(.85$ & $-1.09)$ & 1.04 & $(.91$ & $-1.19)$ \\
\hline Headache & .98 & $(.80$ & $-1.19)$ & .88 & $(.77$ & $-1.00)$ & .88 & $(.77$ & $-1.01)$ \\
\hline Vertigo/dizziness & .91 & $(.71$ & - 1.17) & .95 & $(.82$ & $-1.12)$ & .82 & (.69 & $-.98)$ \\
\hline Acute stress reaction & .98 & $(.71$ & $-1.34)$ & 1.12 & $(.91$ & $-1.37)$ & 1.01 & $(.79$ & $-1.29)$ \\
\hline Feeling/behaving irritable/angry & .79 & $(.41$ & $-1.52)$ & 1.03 & $(.69$ & $-1.54)$ & 1.14 & $(.75$ & $-1.73)$ \\
\hline Sleep disturbance & .86 & $(.72$ & $-1.03)$ & .91 & $(.80$ & $-1.02)$ & .91 & $(.80$ & $-1.04)$ \\
\hline Disturbance of memory/concentration/orientation & .71 & $(.52$ & $-.98)$ & .74 & $(.61$ & $-.90)$ & .91 & $(.77$ & $-1.09)$ \\
\hline Sneezing/nasal congestion & 1.30 & $(.87$ & $-1.93)$ & 1.25 & $(.92$ & $-1.69)$ & .94 & $(.69$ & $-1.28)$ \\
\hline Respiratory problems & .83 & $(.74$ & $-.92)$ & .99 & $(.92$ & $-1.06)$ & 1.02 & $(.94$ & $-1.10)$ \\
\hline Skin problems & 1.05 & $(.88$ & $-1.25)$ & 1.06 & $(.94$ & $-1.18)$ & .91 & $(.78$ & $-1.05)$ \\
\hline Number of NSS $\div$ & .91 & $(.87$ & $-.96)$ & .97 & $(.94$ & $-1.00)$ & .97 & $(.93$ & $-1.00)$ \\
\hline
\end{tabular}

${ }^{a}$ Adjusted for age, gender, SES, depression/anxiety disorder and registry time of the patient in a general practice

$\div$ Count variables, incidence rate ratios (IRR) are provided

${ }^{*} \mathrm{p}<.05$

Table 5: Association (OR, 95\% Cl) between various health symptoms and presence of pigs in 2017, in the study areas (statistically significant results in bold)*

\begin{tabular}{|c|c|c|c|c|c|c|c|c|c|}
\hline & \multicolumn{3}{|c|}{$500 \mathrm{~m}$} & \multicolumn{3}{|c|}{$1000 \mathrm{~m}$} & \multicolumn{3}{|c|}{$2000 \mathrm{~m}$} \\
\hline & $\mathrm{OR}$ & $\mathrm{CI}$ & & OR & $\mathrm{CI}$ & & OR & CI & \\
\hline General weakness/tiredness & .92 & $(.82$ & $-1.03)$ & .97 & $(.89$ & $-1.06)$ & .93 & $(.81$ & $-1.07)$ \\
\hline Abdominal pain & .92 & $(.83$ & $-1.01)$ & .96 & $(.89$ & $-1.03)$ & .94 & $(.84$ & $-1.05)$ \\
\hline Nausea & .80 & $(.59$ & $-1.08)$ & 1.11 & $(.89$ & $-1.37)$ & .80 & $(.58$ & $-1.09)$ \\
\hline Diarrhea & .90 & $(.74$ & $-1.10)$ & 1.02 & $(.88$ & $-1.18)$ & .87 & $(.70$ & $-1.09)$ \\
\hline Eye problems & .96 & $(.72$ & $-1.29)$ & .86 & $(.68$ & $-1.08)$ & .87 & (.61 & $-1.23)$ \\
\hline Pain/pressure chest & .98 & $(.87$ & $-1.11)$ & .99 & $(.90$ & $-1.09)$ & .94 & $(.82$ & $-1.08)$ \\
\hline Palpitations/awareness of heart & .91 & $(.74$ & $-1.13)$ & .85 & $(.73$ & -.99) & 1.08 & $(.84$ & $-1.40)$ \\
\hline Muscle pain & .89 & $(.73$ & $-1.09)$ & 1.06 & $(.90$ & $-1.24)$ & 1.19 & $(.92$ & $-1.55)$ \\
\hline Low back symptom & .89 & $(.77$ & $-1.03)$ & 1.01 & $(.90$ & $-1.12)$ & 1.02 & $(.86$ & $-1.21)$ \\
\hline Headache & .94 & $(.80$ & $-1.10)$ & 1.00 & $(.88$ & $-1.12)$ & 1.00 & $(.83$ & $-1.21)$ \\
\hline Vertigo/dizziness & .80 & $(.66$ & $-.98)$ & .92 & $(.80$ & $-1.06)$ & 1.08 & $(.87$ & $-1.34)$ \\
\hline Acute stress reaction & .95 & $(.75$ & $-1.21)$ & 1.10 & $(.91$ & $-1.32)$ & 1.26 & $(.87$ & $-1.81)$ \\
\hline Feeling/behaving irritable/angry & .60 & $(.34$ & $-1.06)$ & .77 & $(.53$ & $-1.11)$ & .88 & $(.51$ & $-1.52)$ \\
\hline Sleep disturbance & .86 & $(.75$ & $-.99)$ & .90 & $(.81$ & $-1.00)$ & .97 & $(.83$ & $-1.14)$ \\
\hline Disturbance of memory/concentration/orientation & .75 & $(.59$ & $-.95)$ & .89 & $(.76$ & $-1.05)$ & .78 & $(.61$ & $-1.00)$ \\
\hline Sneezing/nasal congestion & .97 & $(.69$ & $-1.36)$ & 1.05 & $(.82$ & $-1.34)$ & .88 & (.63 & $-1.21)$ \\
\hline Respiratory problems & .92 & $(.85$ & $-1.00)$ & .97 & $(.91$ & $-1.03)$ & 1.02 & $(.93$ & $-1.12)$ \\
\hline Skin problems & .98 & $(.86$ & $-1.12)$ & 1.05 & $(.94$ & $-1.16)$ & 1.03 & $(.85$ & $-1.23)$ \\
\hline Number of NSS $\div$ & .92 & (.88 & $-.96)$ & .98 & $(.95$ & $-1.01)$ & .99 & $(.94$ & $-1.04)$ \\
\hline
\end{tabular}

${ }^{a}$ Adjusted for age, gender, SES, depression/anxiety disorder and registry time of the patient in a general practice

$\div$ Count variables, incidence rate ratios (IRR) are provided

p $<.05$ 
Gerbecks, J., Baliatsas, C., Yzermans, C.J., Smit, L.A.M., Huss, A., Heederik, D.J.J., Dückers, M.L.A. Prevalence of non-specific health symptoms in livestock dense areas: Looking beyond respiratory conditions. International Journal of Hygiene and Environmental Health: 2020, 230, 113603

Table 6 Association (OR, 95\% Cl) between various health symptoms and presence of cattle in 2017, in the study areas (statistically significant results in bold)*

\begin{tabular}{|c|c|c|c|c|c|c|c|c|c|}
\hline & \multicolumn{3}{|c|}{$500 \mathrm{~m}$} & \multicolumn{3}{|c|}{$1000 \mathrm{~m}$} & \multicolumn{3}{|c|}{$2000 \mathrm{~m}$} \\
\hline & OR & $\mathrm{CI}$ & & OR & CI & & OR & CI & \\
\hline General weakness/tiredness & .93 & $(.86$ & $-1.01)$ & .93 & $(.84$ & $-1.04)$ & 1.48 & $(.78$ & $-2.80)$ \\
\hline Abdominal pain & .93 & $(.87$ & $-1.00)$ & 1.01 & $(.93$ & $-1.11)$ & 1.40 & $(.84$ & $-2.34)$ \\
\hline Nausea & .90 & $(.73$ & $-1.12)$ & 1.03 & $(.78$ & $-1.36)$ & 1.83 & $(.26$ & $-13.47)$ \\
\hline Diarrhea & .80 & $(.70$ & $-.92)$ & .95 & $(.80$ & $-1.14)$ & .63 & $(.26$ & $-1.55)$ \\
\hline Eye problems & .91 & $(.73$ & $-1.13)$ & .80 & $(.61$ & $-1.03)$ & 1.68 & $(.23$ & $-12.11)$ \\
\hline Pain/pressure chest & .89 & $(.81$ & $-.97)$ & .99 & $(.89$ & $-1.11)$ & 1.32 & $(.70$ & $-2.50)$ \\
\hline Palpitations/awareness of heart & .82 & $(.71$ & $-.96)$ & .93 & $(.77$ & $-1.12)$ & 1.05 & $(.39$ & $-2.87)$ \\
\hline Muscle pain & 1.19 & $(1.03$ & $-1.38)$ & 1.19 & $(.96$ & $-1.47)$ & 1.26 & $(.40$ & $-4.01)$ \\
\hline Low back symptom & .91 & $(.82$ & $-1.01)$ & 1.07 & $(.93$ & $-1.23)$ & 1.12 & $(.59$ & $-2.13)$ \\
\hline Headache & .95 & $(.85$ & $-1.07)$ & .92 & $(.79$ & $-1.07)$ & 1.66 & $(.68$ & $-4.05)$ \\
\hline Vertigo/dizziness & .99 & $(.87$ & $-1.14)$ & .97 & $(.82$ & $-1.14)$ & 1.41 & $(.45$ & $-4.46)$ \\
\hline Acute stress reaction & .98 & $(.82$ & $-1.17)$ & 1.15 & $(.90$ & $-1.48)$ & 1.36 & $(.43$ & $-4.32)$ \\
\hline Feeling/behaving irritable/angry & .96 & $(.68$ & $-1.36)$ & 1.36 & $(.81$ & $-2.27)$ & .99 & $(.14$ & $-7.21)$ \\
\hline Sleep disturbance & .87 & $(.79$ & $-.96)$ & .94 & $(.83$ & $-1.06)$ & 1.62 & $(.71$ & $-3.69)$ \\
\hline Disturbance of memory/concentration/orientation & .97 & $(.82$ & $-1.15)$ & .87 & $(.71$ & $-1.05)$ & .86 & $(.27$ & $-2.73)$ \\
\hline Sneezing/nasal congestion & .87 & $(.68$ & $-1.11)$ & 1.03 & $(.77$ & $-1.37)$ & 2.00 & $(.49$ & $-8.22)$ \\
\hline Respiratory problems & .93 & $(.88$ & $-.98)$ & 1.00 & $(.93$ & $-1.08)$ & 1.34 & $(.85$ & $-2.10)$ \\
\hline Skin problems & .96 & $(.87$ & $-1.07)$ & 1.05 & $(.93$ & $-1.19)$ & 1.96 & $(.72$ & $-5.31)$ \\
\hline Number of NSS $\div$ & .93 & $(.91$ & $-.96)$ & 1.00 & $(.97$ & $-1.04)$ & 1.34 & (1.08 & $-1.67)$ \\
\hline
\end{tabular}

a Adjusted for age, gender, SES, depression/anxiety disorder and registry time of the patient in a general practice

Count variables, incidence rate ratios (IRR) are provided

$* \mathrm{p}<.05$ 